\title{
2 The unique spatial ecology of human hunters
}

3

4 Atle Mysterud $^{1 *}$, Inger M. Rivrud ${ }^{2}$, Vegard Gundersen ${ }^{3}$, Christer M. Rolandsen ${ }^{4}$ and

$5 \quad$ Hildegunn Viljugrein ${ }^{5}$

6

$7{ }^{1}$ Centre for Ecological and Evolutionary Synthesis (CEES), Department of Biosciences,

8 University of Oslo, P.O. Box 1066 Blindern, NO-0316 Oslo, Norway.

$9 \quad{ }^{2}$ Norwegian Institute for Nature Research (NINA), Gaustadalléen 21, NO-0349 Oslo,

10 Norway.

$11{ }^{3}$ Norwegian Institute for Nature Research (NINA), Vormstuguvegen 40, NO-2624

12 Lillehammer, Norway.

$13 \quad{ }^{4}$ Norwegian Institute for Nature Research (NINA), P. O. Box 5685 Torgarden, NO-7485

14 Trondheim, Norway.

$15{ }^{5}$ Norwegian Veterinary Institute, P.O. Box 750 Sentrum, NO-0106 Oslo, Norway.

$17 \quad{ }^{*}$ Corresponding author: atle.mysterud@ibv.uio.no

18

19 
21 Abstract

22 Human hunters are described as 'superpredators' with a unique ecology. Chronic

23 Wasting Disease among cervids and African swine fever among wild boar are emerging

24 wildlife diseases in Europe with huge economic and cultural repercussions.

25 Understanding hunter movements at broad scales has implications for how to control

26 their spread. Here we show, based on the analysis of the settlement patterns and

27 movements of reindeer $(n=9,685)$, red deer $(n=47,845)$, moose $(n=60,365)$, and roe

28 deer $(n=42,530)$ hunters from across Norway $(2001-2017)$, that hunter density was

29 more closely linked to human density than prey density, that hunters were largely

30 migratory, aggregated with increasing regional prey densities and often used dogs.

31 Hunter movements extended across Europe and to other continents. Our results provide

32 extensive evidence that the broad-scale movements and residency patterns of post-

33 industrial hunters relative to their prey differ from those of large carnivores. 
 \\ Introduction}

35 Current globalization and the movements of people and goods are significant contributors to the spatial spread of invasive species, including pathogens ${ }^{1}$, with huge economic and environmental costs ${ }^{2}$. Humans generally follow simple reproducible patterns when travelling ${ }^{3}$, enabling the prediction of disease spreading ${ }^{4}$. The transmission and spatial spread of human infectious diseases are well studied, at local scales linked to commuting ${ }^{5}$ and at broad scales linked to air travel ${ }^{6}$. Human mobility-related factors are also important in the geographic spread of diseases in livestock ${ }^{7}$. The human-mediated spread of wildlife diseases is less well studied but is known to cause surprising outbreaks and long-distance jumps of disease foci ${ }^{8}$. A recent example is the emergence of African swine fever (ASF) among wild boar (Sus scrofa) in Belgium, far from the main epidemic front in eastern Europe ${ }^{9}$. A significant means whereby ASF is spread is human mediated through contaminated meat. Another particularly severe wildlife disease is chronic wasting disease (CWD), which has spread among cervids in North America. CWD prions are present in deer blood ${ }^{10}$ and skeletal muscles ${ }^{11}$, and a potent means of their spread is the careless treatment of offal and other waste by human hunters. Recently, CWD was discovered in the Nordfjella reindeer range in Norway ${ }^{12}$. This represents the first case of CWD in Europe, and there is concern regarding the human-caused introduction of CWD from Norway to continental Europe and the $\mathrm{UK}^{13}$. The European Food Safety Authority Panel-on Biological Hazards noted that hunters during their activity have more opportunities than any other segment of the population for direct exposure to infected material, and they listed this among the risks for CWD spread ${ }^{14}$. EFSA identify that hunting clothes, boots or knives poorly cleaned and used in infected areas could help disseminate contaminated material (e.g. clods of soil attached to their boots), and that faeces of dogs accompanying hunters returning from infected areas/countries can serve as vehicles for prions contributing to the spread of the infectious agent in the environment. 
Due to the emergence of these wildlife diseases, a better understanding of hunter movement patterns at broad scales is needed as a predictor of the hazard of geographic spreading. Human

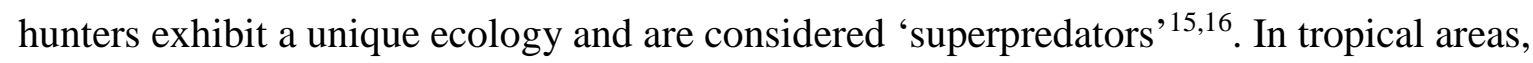
hunting has adverse effects on bird and mammal diversity ${ }^{17}$. In contrast, human hunters have played a key role in the regulation of cervid populations after the extermination of large predators from large parts of Europe and North America. At fine spatial scales within their hunting territory, studies using GPS technology show how hunters follow prey density ${ }^{18-20}$, similar to large carnivores, but the movement of post-industrial hunters at broader scales has never been systematically quantified. Optimal foraging theory predicts that predators with permanent shelter, like a den for large carnivores, should be central place foragers with a restricted radius of activity ${ }^{21}$. However, the superior technology of post-industrial human hunters, including the possibility of longer-distance movement, suggests that their spatial ecology at broad scales should be different compared to that of large carnivores even with permanent housing.

We here analyze unique data on the settlement and movement of 9,685 reindeer (Rangifer tarandus), 47,845 red deer (Cervus elaphus), 60,365 moose (Alces alces), and 42,530 roe deer (Capreolus capreolus) hunters in Norway. We compare the distribution and population density of reindeer, red deer, moose and roe deer relative to that of hunters for each species and the general human population across Norway. We also quantify hunter movements into other parts of Europe, and of 5,651 registered foreign hunters coming to Norway.

\section{Results}

There was a positive and consistent correlation between human and hunter density for all species (all positively correlated with principal component 1; Fig. 1; Supplementary Table 1) at the scale of municipality (mean size $=764 \mathrm{~km}^{2}$, median size $=477 \mathrm{~km}^{2}$ ). The relationship 
between hunter and human density was stronger than the relationship between the population densities of reindeer, red deer and moose and the density of their respective hunters (Table 1). There was no correlation or a low or negative correlation between the density of humans and the density of reindeer, red deer, and moose (Fig. 1; Supplementary table 2). Roe deer density was positively associated with human density, and hence it was difficult to tease apart whether human or roe deer density best predicted density of roe deer hunters (Table 1). Reindeer hunters exhibited a higher density in the biggest cities (Oslo, Bergen, Trondheim) relative to the average (ratio 22) compared to the red deer (ratio 7), moose (ratio 10), and roe deer (ratio 8) hunters (Fig. 1). There was a positive correlation between the incidence of hunters (proportion of hunters among total human population) and the density of the red deer and reindeer, while a similar positive correlation for moose and roe deer was only significant in some regions (west for roe deer, west and north for moose, Table 2). A marked regional increase in the red deer population along the west coast of Norway led to marked increases in the numbers of red deer hunters locally, but also in the adjacent inland regions to the north and in the east on the other side of a continuous mountain range (Table 3). We found no evidence of prey switching, i.e. when predators change to hunt another main prey as their abundances change, as an annual increase in moose hunters in the east was positively correlated with an annual increase in red deer hunters in the same region (Table 3).

Generally, there was a high proportion ( $\sim 50 \%$ ) of migratory hunters among the reindeer, moose, red deer and roe deer hunters (Table 4). For reindeer in Nordfjella (with CWD), there were mainly resident hunters (98.6 \%) in the four communal hunting areas, while there were mainly migratory hunters $(92.4 \%)$ on the two private estates. Among the migratory hunters in the survey, moose (mean $177 \mathrm{~km}$ ) and reindeer (mean $165 \mathrm{~km}$ ) hunters moved the longest distances, followed by red deer (mean $133 \mathrm{~km}$ ) and roe deer (mean $105 \mathrm{~km}$ ) hunters (Table 4). 
107 These distances were found to be considerably longer when movement distances were

108 considered using Google Maps, i.e. the shortest travel distance by car given the road

109 infrastructure (Table 4). There was extensive use of dogs, especially for hunting moose

110 (90.4\%) and roe deer (65.9\%), while this practice was slightly less prominent among red

111 deer (52.8 \%) and was least common for reindeer (17.9\%) (Supplementary Table 3). Among

112 the hunters from Norway hunting abroad (14.9\%), $53.8 \%$ traveled to Sweden, $11.8 \%$ to

113 Poland, and $7.1 \%$ to United Kingdom, while other countries in Europe were visited less

114 frequently (Fig. 2, Supplementary Table 4). Fewer of those hunters going abroad travelled to

115 North America (3.4\%), Africa (4.7\%) and Asia (0.4 \%) to hunt. Among the mean 5,651

116 registered hunters coming from abroad to hunt in Norway (Fig. 2F, Supplementary Table 4),

11796.7 \% came from Europe, mainly Denmark (39.5 \%), Sweden (23.8 \%) and Germany

118 (16.5\%), while $2.6 \%$ were from America, mainly USA and Canada.

\section{Discussion}

120 Understanding the unique ecology of human hunters requires the use of traditional ecological

121 theory but also knowledge of influences related to social organization and desires regarding

122 the recreation among modern humans, with technically superior movement possibilities ${ }^{22}$. A

123 feature of most large terrestrial predators is a lack of migratory behavior because they

124 maintain and protect their territories ${ }^{23}$. Contemporary hunter-gatherers in Paraguay with

125 forced permanent residency fitted expectations of a central place forager with signs of hunters

126 limited to a maximum of $10 \mathrm{~km}$ radius depleting prey close to their settlements ${ }^{24}$. Longer

127 distance mobility of settlements is in anthropology viewed as a 'positioning' strategy ${ }^{25}$. Batek

128 hunter-gatherer residency times in rainforest patches of Malaysia was predicted by the

129 marginal value theorem, and perceptions of resource depletion sparked collective movements

130 of moving residency ${ }^{26}$. In seasonal environments, residency in summer and winter camps are 
described for hunter-gatherer societies as adaptations to increased access of seasonally migratory prey. In contrast, despite that post-industrial hunters have permanent residency, we found widespread migratory behavior among such hunters (Table 4), and the correlation between prey density and hunter density at broad scales was low.

The proportion of migratory hunters and the distance travelled depended on the particular cervid species and the population density of prey, but was for reindeer also largely dependent on the management system (communal versus private estates; Table 4). Reindeer hunting on private land in Norway is more expensive compared to red deer and moose hunting, but it is often cheap and exclusively open to local hunters in communal areas. On private estates, there was a higher relative density of reindeer hunters from the biggest cities of Norway (Oslo, Bergen and Trondheim), which may be partly due to higher disposable incomes in large cities than in other parts of the country. Hunting in Norway is mainly conducted to obtain meat and for recreation, rather than to collect trophies ${ }^{27}$. Consistent with this situation, travel distances were longer for the large-bodied cervids than for the smaller roe deer. The distribution of roe deer also overlapped more with the human density, contributing to a greater number of local resident hunters. Many hunters also travelled from Norway across Europe (Fig. 2E) and to other continents to hunt, and many hunters from abroad came to Norway to hunt (Fig. 2F).

Together, these movements pose a hazard regarding the introduction of wildlife diseases unless they are wisely managed. Dispersal is generally separated into the processes of immigration, emigration and colonization. Immigration and emigration of hunters alone is not sufficient to spread wildlife disease, and successful colonization of disease depend on contamination by hunters, dogs or equipment resulting in successful establishment in a new area. We point to the extensive use of dogs among European hunters as a potentially important difference from the North American CWD situation. CWD prions remain infectious 
155 in the feces of coyotes (Canis latrans) for up to 3 days postingestion ${ }^{28}$. While dogs are

156 occasionally used for white-tailed deer hunting in North America ${ }^{29}$, the use of dogs is much

157 more extensive in Europe. In particular moose and roe deer hunters nearly always use dogs

158 for hunting, as evidenced in our survey (Supplementary Table 3), and this practice is common

159 in Scandinavia. Additionally, bones with meat residue are often left in nature in rural areas or

160 fed to dogs. Elk (Cervus canadensis) carcasses are regarded as hot spots for CWD

161 transmission ${ }^{30}$, and experimental studies show that carcasses provide an important

162 environmental source of prions sparking new CWD epidemics ${ }^{31}$. Decaying carcasses provide

163 nutrients to plants and attract herbivore grazing, which is important for the transmission cycle

164 of $\mathrm{CWD}^{31}$ and anthrax ${ }^{32}$. Urine and feces from dogs may similarly provide nutrients to plants

165 and may serve as attraction points for grazing animals. In continental Europe, the use of dogs

166 is important during drive hunts, which often involve hunting in new areas each day. Under

167 such practices, when dogs eat from carcasses $^{33}$, dog feces with infected ASF virus may be

168 eaten by wild boars. Hence, mitigation measures aimed at informing hunters of risks are

169 crucial. In contrast to carnivores, hunters could be receptive to information and other

170 incentives about risks associated with wildlife disease and could adjust their behavior

171 accordingly ${ }^{34}$.

172 The issue of wildlife population regulation is becoming urgent due to the diminishing number

173 of hunters in many western societies in both Europe and North America ${ }^{35}$. Understanding the

174 functional and numerical responses is key to understanding the population dynamic impact of

175 any predator on their prey and depends on whether the predator is a prey generalist or

176 specialist. Prey switching from low to high abundance of a given prey (a sigmoidal, type III,

177 functional response) is predicted for generalist predators such as humans. However, we found

178 a positive correlation in the annual growth of moose and red deer hunters in the east, which is 
a pattern opposite to expectations for a generalist predator switching between prey. The

180 functional responses of human hunters arise from different limitations, as a greater number of

181 other game species means more opportunities. Furthermore, the numerical response of

182 humans is not linked to reproduction as in natural predators but to the recruitment of hunters

183 from the human population, in addition to aggregation (movements) responses. There was a

184 clear numerical aggregation response to regionally increasing red deer populations along the

185 west coast of Norway, involving hunters recruited from eastern inland areas with low red deer

186 densities. Such rational choices have also been found among willow grouse hunters in

187 Sweden, who frequently switch hunting areas and return to the same area more often if they

188 are successful ${ }^{36}$. In other cases, socioeconomic aspects restrict the optimal movement of

189 hunters relative to prey densities. In contrast to natural predators, humans fall into

190 socioeconomic groups with different motivations, norms and attitudes as well as economic

191 and time restrictions on hunting that affect their movement choices and resulting offtake ${ }^{27}$.

192 How far and frequently different hunters are willing to travel will affect the ability of hunters

193 to control wildlife populations and the associated income obtained by rural economies.

194 The ecological and evolutionary impacts of human hunters differ from those of large

195 carnivores ${ }^{15}$. Here, we provide extensive evidence that the broad-scale movements and

196 residency patterns of post-industrial hunters relative to their prey differ from those of large

197 carnivores. These insights into broader-scale hunter movements are important for meeting the

198 challenge of containing wildlife diseases, the ability to control wildlife populations, and for

199 economies related to wildlife. The potential adverse effects of an increasingly globalized

200 hunting tourism industry, often involving urban well-travelled hunters, deserve further

201 attention. 


\section{Methods}

\section{Study area}

Our study area comprised the whole of Norway. We define four regions of Norway: east (counties 1 = Østfold; 2 = Akershus; 3 = Oslo; 4 = Hedmark; 5 = Oppland; 6 = Buskerud), west $(11=$ Rogaland; 12 = Hordaland; 14 = Sogn \& Fjordane; 15 = Møre \& Romsdal; 16 = Sør-Trøndelag), south (7 = Vestfold; 8 = Telemark; 9 = Aust-Agder; 10 = Vest-Agder), and north $(17=$ Nord-Trøndelag; 18 = Nordland; 19 = Troms; 20 = Finnmark $)$.

\section{Population density index of cervids}

We included data on all four native wild cervid species. From Statistics Norway

(www.ssb.no), we retrieved data on harvest statistics for red deer, moose, and roe deer for all municipalities in Norway. To calculate an index for population densities, we divided the harvest numbers by the so-called qualifying area used by management to estimate cervid habitat, which typically consists mainly of forest and bog areas. This index has been widely applied and tested with independent data to assess their reliability as indices of population trends. This population density index correlated with population density estimated from cohort analysis in red deer ${ }^{37}$ and moose both within and between regions ${ }^{38}$. For roe deer, population density index is used in analysis of population dynamics and regarded a very good proxy for population size $\mathrm{e}^{39,40}$. The population density index has been used widely in demographic studies ${ }^{41,42}$, showing clear links to deer performance such as body mass ${ }^{41}$, age at first reproduction and timing of ovulation ${ }^{42}$, suggesting it reflects density relative to resource levels and that density levels are strongly affected by management differences ${ }^{41}$. The population density index was also successful in predicting incidence of tick-borne diseases ${ }^{43}$. Due to a different scale of management for reindeer, harvest statistics were available at the scale of 23 management areas. To obtain comparable data, we therefore overlaid the 23 the 
management regions with the map of municipalities in GIS. We calculated the proportion of each reindeer management region belonging to a set of municipalities, assuming that the overall harvest in the municipality was proportional to the area of each municipality in the reindeer management region.

\section{Hunter settlement patterns}

From Statistics Norway, we retrieved data on the residency municipalities of all reindeer ( $\mathrm{n}=$ 9,685), red deer $(n=47,845)$, moose $(n=60,365)$, and roe deer $(n=42,530)$ hunters for the hunting season of 2017/18. These data come from the annual mandatory reporting scheme for hunters in Norway, where hunters have to provide data on their harvest to obtain their next year's hunting license. Due to privacy concerns, Statistics Norway does not distribute data from municipalities with between 1 and 5 hunters, and we set the value for these municipalities at 2.5 in the analysis. In addition, a total of 35 reindeer hunters, 45 red deer hunters, 85 moose hunters and 40 roe deer hunters lived abroad and were therefore excluded. To calculate the density of hunters and their incidence in the human population, we also retrieved human population numbers for each municipality in 2017 from Statistics Norway (www.ssb.no).

\section{Hunter movements at broad scales}

We used the distance between the center Universal Transverse Mercator (UTM) coordinates of the residency and hunting municipality to calculate the distance travelled for hunting. We also used Google Maps to calculate the estimated travel distance when travelling by car. We defined a resident hunter as one who hunts and lives in the same municipality, while a migratory hunter lives and hunts in different municipalities (mixed hunters do both). We used different sources for data on broad-scale hunter movements (Table 4). 
(1) For roe deer, in the mandatory hunter reporting system, both the municipality of residency

251 and municipality of successful roe deer hunting were recorded and provided by Statistics

252 Norway. Due to privacy concerns, we did not obtain information in cases where only 1 or 2

253 hunters were recorded, and we set those values to 1.5. It should be noted that if people hunt in

254 several municipalities, they will be double-counted under this particular statistic.

255 (2) For the Nordfjella reindeer area (where chronic wasting disease occurs; $2000 \mathrm{~km}^{2}$ ), we 256 approached the secretaries of all the five communal mountain boards ("Fjellstyrer") for each 257 municipality around Nordfjella (Aurland and Lærdal in Sogn og Fjordane County; Hemsedal, 258 Hol and $\AA$ l in Buskerud County), which are the reindeer areas where CWD has been detected, 259 and we obtained data from three of them. These mountain boards control the access of hunters 260 through sales of licenses. We similarly approached the landowners of two of the largest 261 private estates in Nordfjella (NF522 Sanddalen, NF523 Bjordalen). We asked for the number 262 of hunters and their residential municipality in 2016.

263 (3) For the Knutshø reindeer area $\left(1780 \mathrm{~km}^{2}\right)$, we approached all hunters $(\mathrm{n}=180)$ who 264 accessed the area on roads on 21 selected days during the hunting season (from $20^{\text {th }}$ August to $26521^{\text {st }}$ September, 2011). The aim of the study was to collect key demographic information and 266 visitation characteristics of the hunters, including their residency address. The response rate of 267 the survey was $88 \%$.

268 (4) For all species, we performed a broader survey on CWD and management in Norway in 269 which we asked respondents in a questionnaire about where they hunt, what they hunt, and if 270 they use dogs (see Supplementary information). The survey was sent to members of the 271 Norwegian Association of Hunters and Anglers (NJFF) and distributed through the main 272 online cervid information portal of Norway (“Hjorteviltportalen”) as well as on the main 273 Norwegian hunter groups on Facebook (“Reindeer in Nordfjella”, "Red deer and red deer 
274 hunting”, "Red deer and red deer management”, “Moose and moose hunting”, "Roe deer and 275 roe deer hunting”). The survey was initiated on the $21^{\text {st }}$ of December 2018 and closed on the

276

277

278

279

280

281

282

283

284

285

286

287

288

289

290

291

292

293

294

295

296 $4^{\text {th }}$ of February 2019. Due to this design, it was not possible to calculate response rates, and online surveys may lead to bias. To assess potential bias, we compared the consistency to high-quality data for roe deer and reindeer. Furthermore, the main intention of the survey was to obtain comparable data from all species, and any bias is likely to be consistent across species.

(5) From Statistics Norway, we also retrieved data on all foreign hunters being registered in the hunter database for the years 2014-2018 $(n=5,246-6,506)$, as well as all those paying license a given year, indicating they are actually hunting $(n=1,927-2,136)$. The two metrics were highly correlated at the country level $(r=0.998)$, and we used movement network for registered hunters to increase sample size.

\section{Statistical analysis}

Analyses were conducted in R vs. 3.6.0.

Spatial analysis. We applied principal component analysis to the correlation matrix and a biplot (utilizing library 'ggfortify' in R) of the two first principal components to explore the correlation between human density, hunter density and prey densities (municipality level). The vector of loadings indicates the importance of the variable for the respective principal components, and the angles between the vectors indicate how the variables correlate with one another, where the smaller the angle, the stronger the positive correlation is. Cervid, human and hunter densities were ln-transformed to reduce skewness in the data, and the three northernmost counties were excluded to reduce the amount of zero values. For testing associations between hunter densities in relation to human densities and prey densities and 
between hunter incidence and prey densities, we used 1) pairwise (Spearman/Pearson)

298 correlations including 95 \% confidence intervals, calculated using bootstrapping with library 'boot' in R, and 2) Poisson regression models with an offset term (total municipality area or inhabitants in a municipality). Spatial correlations were accounted for by the BYM model

301 (also called the convolution model ${ }^{44}$ ), which uses two sets of random effects: one spatially 302 structured to model spatial autocorrelation and the other spatially unstructured to describe 303 residual unstructured heterogeneity. We applied a variant of the BYM model, where the two 304 random effects are standardized to have variance equal to one (BYM2 model in INLA). The models were fitted using R-INLA ${ }^{45}$. The INLA method performs approximate Bayesian inference based on an integrated nested Laplace. We used the default vague priors of INLA.

307 Temporal analysis. Time series at the county level were detrended by first-order differencing $308\left(\Delta_{t}=\mathrm{Y}_{t}-\mathrm{Y}_{\mathrm{t}-1)}\right.$. We analyzed changes in the numbers of red deer hunters from one year to another via generalized least square regression ('nlme' library in R), which allowed us to 310 account for heterogeneous variation between counties. Changes in the numbers of red deer 311 hunters were modeled as a function of the annual changes in the harvest size of red deer in the previous year (harvest size year t-1 - harvest size year t-2). The explanatory variables in the model were the changes in deer harvest numbers in the west region as well as the changes in

314 deer harvest numbers in the respective region of the county. Potential remaining temporal 315 autocorrelation was tested by including an AR1-term. The significance of the explanatory 316 variables was indicated by showing the change in AICc (using ML estimation) when the 317 variable was deleted from the model. The changes in deer harvest numbers in specific 318 counties were tested as an alternative, but this approach resulted in similar or slightly higher 319 AICc levels. Counties were included as both a fixed effect and a variance-dependent factor. 320 Models were fitted separately for each region. For the east region recruiting red deer hunters 
to the west region, we also ran a model to determine whether there was prey switching

322 (increase in red deer hunters at the expense of moose hunting) or not.

323

324

325

326

327

328

\section{Data availability}

Data are available at Dryad, Dataset, https://doi.org/10.5061/dryad.1jwstqjr9.

\section{Code availability}

Analysis code are available at Dryad, Dataset, https://doi.org/10.5061/dryad.1jwstqjr9.

\section{References}

1. Daszak, P., Cunningham, A. A. \& Hyatt, A. D. Emerging infectious diseases of wildlife - Threats to biodiversity and human health. Science 287, 443-449 (2000).

2. Pimentel, D., Lach, L., Zuniga, R. \& Morrison, D. Environmental and economic costs of nonindigenous species in the United States. BioScience 50, 53-65 (2000).

3. González, M. C., Hidalgo, C. A. \& Barabási, A.-L. Understanding individual human mobility patterns. Nature 453, 779-782 (2008).

4. Wesolowski, A., Eagle, N., Tatem, A. J., et al. Quantifying the impact of human mobility on malaria. Science 338, 267(2012).

5. Charu, V., Zeger, S., Gog, J., et al. Human mobility and the spatial transmission of influenza in the United States. PLOS Computational Biology 13, e1005382(2017).

6. Brownstein, J. S., Wolfe, C. J. \& Mandl, K. D. Empirical evidence for the effect of airline travel on inter-regional influenza spread in the United States. PLOS Med 3, e401(2006). 
7. Rivas, A. L., Kunsberg, B., Chowell, G., Smith, S. D., Hyman, J. M. \& Schwager, S. J. Human-mediated foot-and-mouth disease epidemic dispersal: disease and vector clusters. J Vet Med Sci Ser B 53, 1-10 (2006).

8. Price, S. J., Garner, T. W. J., Cunningham, A. A., Langton, T. E. S. \& Nichols, R. A. Reconstructing the emergence of a lethal infectious disease of wildlife supports a key role for spread through translocations by humans. Proc $R$ Soc Lond Ser B 283, (2016).

9. European Food Safety Authority (EFSA), Boklund, A., Cay, B., et al. Epidemiological analyses of African swine fever in the European Union (November 2017 until November 2018). EFSA Journal 16, e05494(2018).

10. Mathiason, C. K., Powers, J. G., Dahmes, S. J., et al. Infectious prions in the saliva and 354 blood of deer with Chronic Wasting Disease. Science 314, 133(2006).

11. Angers, R. C., Browning, S. R., Seward, T. S., et al. Prions in skeletal muscles of deer with chronic wasting disease. Science 311, 1117(2006).

12. Benestad, S. L., Mitchell, G., Simmons, M., Ytrehus, B. \& Vikøren, T. First case of chronic wasting disease in Europe in a Norwegian free-ranging reindeer. Vet Res 47, 88(2016).

13. Department for Environment Food \& Rural Affairs. What is the risk of a cervid TSE being introduced from Norway into Great Britain? Qualitative risk assessment. (Department for Environment Food \& Rural Affairs, https://assets.publishing.service.gov.uk/government/uploads/system/uploads/atta chment_data/file/733407/DEFRA_QRA_TSE_in_cervids_June2018_v1.pdf, 2018).

14. EFSA Panel-on Biological Hazards (BIOHAZ), Koutsoumanis, K., Allende, A., et al. Update on chronic wasting disease (CWD) III. EFSA Journal 17, e05863(2019). 
15. Darimont, C. T., Fox, C. H., Bryan, H. M. \& Reimchen, T. E. The unique ecology of human predators. Science 349, 858-860 (2015).

16. Worm, B. A most unusual (super)predator. Science 349, 784(2015).

17. Benítez-López, A., Alkemade, R., Schipper, A. M., et al. The impact of hunting on tropical mammal and bird populations. Science 356, 180(2017).

18. Lebel, F., Dussault, C., Massé, A. \& Côté, S. D. Influence of habitat features and hunter behavior on white-tailed deer harvest. J Wildl Manage 76, 1431-1440 (2012).

19. Brøseth, H. \& Pedersen, H. C. Hunting effort and game vulnerability studies on a small scale: a new technique combining radio-telemetry, GPS and GIS. J Appl Ecol 37, 182-190 (2000).

20. Jones, M. D., Berl, J. L., Tri, A. N., Edwards, J. W. \& Spiker, H. A. Fine-scale movements and spatial behaviors of bear hunters: Combining GPS with survey methods. Hum Dimens Wildl 22, 362-373 (2017).

21. Winterhalder, B. in Hunter-gatherer foraging strategies: ethnographic and archeological analyses. (eds Winterhalder, B. \& Smith, E. A.) UC Davis, 1981).

22. Suni, J. \& Pesonen, J. Hunters as tourists - an exploratory study of push-pull motivations. Scandinavian Journal of Hospitality and Tourism 19, 175-191 (2019).

23. Fryxell, J. M., Greever, J. \& Sinclair, A. R. E. Why are migratory ungulates so abundant? Am Nat 131, 781-798 (1988).

24. Hill, K., Padwe, J., Bejyvagi, C., et al. Impact of hunting on large vertebrates in the Mbaracayu reserve, Paraguay. Cons Biol 11, 1339-1353 (1997). archaeological site formation. American Antiquity 45, 4-20 (1980). 
26. Venkataraman, V. V., Kraft, T. S., Dominy, N. J. \& Endicott, K. M. Hunter-gatherer residential mobility and the marginal value of rainforest patches. PNAS 114, 3097(2017).

27. Andersen, O., Wam, H. K., Mysterud, A. \& Kaltenborn, B. Applying deer hunter typologies to harvest management. J Wildl Manage 78, 1282-1292 (2014).

28. Nichols, T. A., Fischer, J. W., Spraker, T. R., Kong, Q. \& Vercauteren, K. C. CWD prions remain infectious after passage through the digestive system of coyotes (Canis latrans). Prion 9, 367-375 (2015).

29. Godwin, C., Schaefer, J. A., Patterson, B. R. \& Pond, B. A. Contribution of dogs to white-tailed deer hunting success. J Wildl Manage 77, 290-296 (2013).

30. Dugal, C. J., van Beest, F. M., Vander Wal, E. \& Brook, R. K. Targeting hunter distribution based on host resource selection and kill sites to manage disease risk. Ecol Evol 3, 4265-4277 (2013).

31. Miller, M. W., Williams, E. S., Hobbs, N. T. \& Wolfe, L. L. Environmental sources of prion transmission in mule deer. Emerg Infect Dis 10, 1003-1006 (2004).

32. Turner, W. C., Kausrud, K. L., Krishnappa, Y. S., et al. Fatal attraction: vegetation responses to nutrient inputs attract herbivores to infectious anthrax carcass sites. Proc R Soc Lond Ser B 281, (2014).

33. Alberto, J. R., Serejo, J. P. \& Vieira-Pinto, M. in Game meat hygiene in focus: Microbiology, epidemiology, risk analysis and quality assurance (eds Paulsen, P., Bauer, A., Vodnansky, M., Winkelmayer, R. \& Smulders, F. J. M.) 101-105 (Wageningen Academic Publishers, Wageningen, 2011).

34. Needham, M. D., Vaske, J. J. \& Petit, J. D. Risk sensitivity and hunter perceptions of Chronic Wasting Disease risk and other hunting, wildlife, and health risks. Hum Dimens Wildl 22, 197-216 (2017). 
35. Massei, G., Kindberg, J., Licoppe, A., et al. Wild boar populations up, numbers of hunters down? A review of trends and implications for Europe. Pest. Manag. Sci. 71, 492-500 (2015).

36. Asmyhr, L., Willebrand, T. \& Hörnell-Willebrand, M. The optimal foraging theory, crowding and Swedish grouse hunters. Eur J Wildl Res 59, 743-748 (2013).

37. Mysterud, A., Meisingset, E. L., Veiberg, V., et al. Monitoring population size of red deer: an evaluation of two types of census data from Norway. Wildl Biol 13, 285-298 (2007).

38. Ueno, M., Solberg, E. J., Iijima, H., Rolandsen, C. M. \& Gangsei, L. E. Performance of hunting statistics as spatiotemporal density indices of moose (Alces alces) in Norway. Ecosphere 5, 13(2014).

39. Grøtan, V., Sæther, B.-E., Engen, S., et al. Climate causes large-scale spatial synchrony in population fluctuations of a temperate herbivore. Ecol 86, 1472-1482 (2005).

40. Mysterud, A. \& Østbye, E. The effect of climate and density on individual and population growth of roe deer Capreolus capreolus at northern latitudes - the Lier valley, Norway. Wildl Biol 12, 321-329 (2006).

41. Mysterud, A., Yoccoz, N. G., Stenseth, N. C. \& Langvatn, R. The effects of age, sex and density on body weight of Norwegian red deer: evidence of density-dependent senescence. Proc R Soc Lond Ser B 268, 911-919 (2001).

42. Langvatn, R., Mysterud, A., Stenseth, N. C. \& Yoccoz, N. G. Timing and synchrony of ovulation in red deer constrained by short northern summers. Am Nat 163, 763772 (2004).

43. Mysterud, A., Easterday, W. R., Stigum, V. M., Aas, A. B., Meisingset, E. L. \& Viljugrein, H. Contrasting emergence of Lyme disease across ecosystems. Nature Comm 7, Article 11882(2016). 
44. Congdon, P. D. Bayesian hierarchical models: with applications using R. 2nd edition. (Chapman and Hall, 2019).

45. Bakka, H., Rue, H., Fuglstad, G. A., et al. Spatial modelling with R-INLA: a review. arXiv 1802.06350, (2018).

\section{Acknowledgements}

We are grateful to Trond Amund Steinset at Statistics Norway for providing data on hunters, to NJFF for distributing the survey link, to Roald Vang at the Norwegian Institute for Nature Research for technical assistance with setting up the online survey, and to Chris Darimont for constructive comments to a previous draft. The online survey was partly financed by the Norwegian Environment Agency.

\section{Contributions}

AM conceived the idea, designed the study and wrote the first draft. AM and IMR produced the figures, and HV led the analysis and made Fig. 1F. AM collected data on reindeer hunters in Nordfjella; VG collected data on reindeer hunters in Knutshø; and CMR organized the online survey. All authors commented on and approved further drafts.

\section{Competing interests}

The authors declare no competing interests. 
Figure 1. The population density of hunters, prey and humans. The population density of humans hunting (A) reindeer, (B) red deer, (C) moose, and (D) roe deer and the (E) overall human population density of Norway. (F) A principal component analysis of the relationship between the densities of the four species of cervids, their respective hunters and overall human density. The first principal component (describing $45 \%$ of variation in the data) show the stronger correlation between human and hunter density, compared to hunter and deer density. There was stronger correlation of hunter and human density than between hunter and 471 prey density. The second principal component (describing 25\% of variation in the data) shows 472 the spatial contrast of moose densities against red deer and red deer hunter densities.

Figure 2. The travel networks of human hunters relative to population density of prey.

Travel networks of (A) reindeer, (B) red deer, (C) moose and (D) roe deer hunters in Norway with the population density of reindeer, red deer, moose, and roe deer at the scales of municipality in Norway, in the background. (E) Movement of big game hunters from Norway

477 into Europe and back (at the scale of municipality in Norway, county in Sweden and the 478 center point of the country in the rest of Europe). (F) Movement of hunters coming from 479 abroad to hunt in Norway. 
Table 1. Relationships between spatial hunter, human and prey density. Spatial regression analysis of hunter density relative to human and prey density at municipality scale across whole of Norway $(n=424$ for moose; $n=316$ for red deer, roe deer and reindeer, for which region north is excluded due to species being absent or in low population numbers). Density is short for population density and was scaled to zero mean and variance one. Numbers $0.025,0.5$ and 0.975 refer to quantiles of the posterior distributions. Incidence rate ratios (IRR) show the expected change in hunter density corresponding to a change of 1 SD in human or cervid population density.

\begin{tabular}{|c|c|c|c|c|c|c|c|c|}
\hline Parameter & mean & sd & 0.025 & 0.5 & 0.975 & IRR & $\operatorname{IRR}(0.025)$ & $\operatorname{IRR}(0.975)$ \\
\hline \multicolumn{9}{|l|}{ A. Red deer hunters } \\
\hline Intercept & -1.387 & 0.141 & -1.666 & -1.387 & -1.113 & & & \\
\hline $\log ($ human density) & 1.008 & 0.031 & 0.947 & 1.008 & 1.069 & 2.74 & 2.58 & 2.91 \\
\hline $\log ($ Red deer density + 0.01) & 0.365 & 0.052 & 0.263 & 0.365 & 0.467 & 1.44 & 1.30 & 1.60 \\
\hline Total precision (spatial and unstructured) & 3.131 & 0.476 & 2.281 & 3.104 & 4.145 & & & \\
\hline Proportion of variance explained by spatial effect & 0.779 & 0.062 & 0.643 & 0.784 & 0.886 & & & \\
\hline Intercept & -1.872 & 0.017 & -1.906 & -1.872 & -1.84 & & & \\
\hline $\log ($ human density) & 0.896 & 0.034 & 0.829 & 0.896 & 0.962 & 2.45 & 2.29 & 2.62 \\
\hline $\log ($ Moose density + 0.01) & 0.534 & 0.051 & 0.436 & 0.534 & 0.635 & 1.71 & 1.55 & 1.89 \\
\hline Total precision (spatial and unstructured) & 1.935 & 0.264 & 1.458 & 1.922 & 2.491 & & & \\
\hline Proportion of variance explained by spatial effect & 0.848 & 0.048 & 0.739 & 0.853 & 0.927 & & & \\
\hline \multicolumn{9}{|l|}{ C. Reindeer hunters } \\
\hline $\log ($ human density) & 1.182 & 0.066 & 1.053 & 1.182 & 1.312 & 3.26 & 2.87 & 3.71 \\
\hline $\log ($ Reindeer density + 0.01) & 0.595 & 0.063 & 0.472 & 0.596 & 0.718 & 1.81 & 1.60 & 2.05 \\
\hline Total precision (spatial and unstructured) & 0.995 & 0.221 & 0.620 & 0.976 & 1.483 & & & \\
\hline Proportion of variance explained by spatial effect & 0.710 & 0.112 & 0.464 & 0.721 & 0.895 & & & \\
\hline
\end{tabular}




\section{Roe deer hunters}

\section{Intercept}

$\begin{array}{ll}-1.467 & 0.135\end{array}$

$-1.747$

log(human density)

1.0120 .043

$\log (\text { Roe deer density }+0.01)^{1}$

$0.243 \quad 0.049$

$\begin{array}{ll}-1.462-1.215 \\ 1.011 & 1.097\end{array}$

$1.206 \quad 0.151$

0.927

$1.011 \quad 1.097$

$\begin{array}{ll}1.011 & 1.097 \\ 0.242 & 0.339\end{array}$

2.75

2.53

3.00

Total precision (spatial and unstructured)

0.922

$1.203 \quad 1.511$

Proportion of variance explained by spatial effect

0.9650 .020

0.918

0.969

0.992

$1.28 \quad 1.16$

1.40

${ }^{1}$ Roe deer density is correlated with human density (Supplementary table 2) and the relationship between roe deer density and roe deer hunters are stronger if excluding human density from the model. 
Table 2. Relationships between spatial hunter incidence, human and prey density. Spatial analysis of incidence of hunters relative to prey density at municipality scale across whole of Norway $(n=424$ for moose; $n=316$ for red deer, roe deer and reindeer, for which region north is excluded due to species being absent or in low population numbers). Density is short for population density and was scaled to zero mean and variance one. Numbers $0.025,0.5$ and 0.975 refer to quantiles of the posterior distributions. Incidence of hunters refers to proportion of hunters out of total human population. Incidence rate ratios (IRR) show the expected change in hunter incidence corresponding to a change of 1 SD in cervid population density.

\begin{tabular}{|c|c|c|c|c|c|c|c|c|}
\hline & mean & sd & 0.025 & 0.5 & 0.975 & IRR & $\operatorname{IRR}(0.025)$ & $\operatorname{IRR}(0.975)$ \\
\hline \multicolumn{9}{|l|}{ A. Red deer hunters } \\
\hline Intercept & -4.822 & 0.239 & -5.275 & -4.828 & -4.338 & & & \\
\hline $\log ($ Red deer density +0.01$)$ & 0.378 & 0.090 & 0.202 & 0.378 & 0.553 & 1.46 & 1.22 & 1.74 \\
\hline Total precision (spatial and unstructured) & 0.756 & 0.103 & 0.566 & 0.753 & 0.970 & & & \\
\hline Proportion of variance explained by spatial effect & 0.918 & 0.033 & 0.840 & 0.923 & 0.969 & & & \\
\hline \multicolumn{9}{|l|}{ B. Moose hunters } \\
\hline Intercept & -4.448 & 0.137 & -4.717 & -4.448 & -4.179 & & & \\
\hline $\log ($ Moose density +0.01$)$ & 0.768 & 0.112 & 0.550 & 0.767 & 0.988 & 2.16 & 1.73 & 2.69 \\
\hline Region south vs west & 0.993 & 0.271 & 0.460 & 0.993 & 1.525 & & & \\
\hline Region east vs west & 0.527 & 0.265 & 0.005 & 0.527 & 1.047 & & & \\
\hline Region north vs west & -0.285 & 0.198 & -0.680 & -0.283 & 0.098 & & & \\
\hline $\log ($ densMoose $16+0.01)):$ Region south & -0.568 & 0.227 & -1.016 & -0.567 & -0.124 & 1.22 & 0.63 & 2.37 \\
\hline $\log ($ densMoose16 + 0.01)): Region east & -0.607 & 0.278 & -1.153 & -0.607 & -0.063 & 1.17 & 0.55 & 2.52 \\
\hline $\log ($ densMoose16 + 0.01)):Region north & 0.116 & 0.155 & -0.184 & 0.115 & 0.424 & 2.42 & 1.44 & 4.10 \\
\hline Precision for spatial effect & 0.583 & 0.045 & 0.498 & 0.582 & 0.676 & & & \\
\hline
\end{tabular}

\section{Reindeer hunters}




\begin{tabular}{|c|c|c|c|c|c|c|c|c|}
\hline Intercept & -6.430 & 0.300 & -7.025 & -6.428 & -5.844 & & & \\
\hline $\log ($ Reindeer density +0.01$)$ & 0.781 & 0.074 & 0.634 & 0.782 & 0.924 & 2.18 & 1.89 & 2.52 \\
\hline Total precision (spatial and unstructured) & 0.682 & 0.146 & 0.433 & 0.670 & 1.005 & & & \\
\hline Proportion of variance explained by spatial effect & 0.748 & 0.100 & 0.524 & 0.759 & 0.909 & & & \\
\hline \multicolumn{9}{|l|}{ D. Roe deer hunters } \\
\hline Intercept & -5.014 & 0.193 & -5.389 & -5.016 & -4.626 & & & \\
\hline $\log ($ Roe deer density +0.01$)$ & 0.339 & 0.088 & 0.166 & 0.339 & 0.513 & 1.40 & 1.18 & 1.67 \\
\hline Region south vs west & 1.087 & 0.237 & 0.621 & 1.087 & 1.552 & & & \\
\hline Region east vs west & 0.818 & 0.198 & 0.430 & 0.818 & 1.208 & & & \\
\hline $\log ($ Roe deer density + 0.01):Region south & -0.606 & 0.150 & -0.900 & -0.606 & -0.312 & 0.77 & 0.48 & 1.22 \\
\hline $\log ($ Roe deer density + 0.01):Region east & -0.573 & 0.135 & -0.838 & -0.573 & -0.309 & 0.79 & 0.51 & 1.22 \\
\hline Total precision (spatial and unstructured) & 0.668 & 0.087 & 0.505 & 0.666 & 0.845 & & & \\
\hline Proportion of variance explained by spatial effect & 0.952 & 0.025 & 0.891 & 0.956 & 0.987 & & & \\
\hline
\end{tabular}


Table 3. Temporal variation of hunter numbers. Generalized least squares regression analysis of annual increases in red deer hunter numbers in different regions of Norway (20012017) as a function of the annual changes $(\Delta)$ in the harvest size of red deer from the previous year (harvest size year t-1 - harvest size year t-2). We tested whether the annual changes in deer hunter numbers were associated with changes in deer harvest numbers in the west region or with changes in the respective region of the county. The west region has shown major growth in the red deer population. $\triangle \mathrm{AICc}$ is the effect of removing the variable in the given row. County numbers: 1 = Østfold; 2 = Akershus; 3 = Oslo; 4 = Hedmark; 5 = Oppland; 6 = Buskerud; 7 = Vestfold; 8 = Telemark; 9 = Aust-Agder; 10 = Vest-Agder; 11 = Rogaland; 12 = Hordaland; 14 = Sogn \& Fjordane; 15 = Møre \& Romsdal; 16 = Sør-Trøndelag; 17 = NordTrøndelag; 18 = Nordland. Adding an AR-1 term did not improve model fit ( $\Delta$ AICc ranged between $-0.4-2.9)$.

\begin{tabular}{|c|c|c|c|c|c|}
\hline & Estimate & $\mathrm{SE}$ & $\mathrm{t}$ & $\mathrm{P}$ & $\triangle \mathrm{AICc}$ \\
\hline \multicolumn{6}{|l|}{$\begin{array}{l}\text { West Norway (incl. Sør- } \\
\text { Trøndelag) }\end{array}$} \\
\hline Intercept & -15.90 & 19.43 & -0.82 & 0.416 & \\
\hline$\Delta$ (Harvest size West)_lag1 & 0.029 & 0.005 & 5.97 & $<0.001$ & 28.8 \\
\hline County (11 vs 14) & 80.47 & 26.98 & 2.98 & 0.004 & \\
\hline County (12 vs 14$)$ & 75.40 & 26.98 & 2.80 & 0.007 & \\
\hline County (15 vs 14) & 39.40 & 26.98 & 1.46 & 0.149 & \\
\hline County (16 vs 14) & 112.20 & 26.98 & 4.16 & $<0.001$ & 10.0 \\
\hline \multicolumn{6}{|l|}{ East Norway } \\
\hline Intercept & 27.11 & 9.381 & 2.89 & 0.005 & \\
\hline$\Delta$ (Harvest size West)_lag1 & 0.010 & 0.002 & 4.01 & $<0.001$ & 12.9 \\
\hline$\Delta$ (Harvest size East)_lag1 & -0.143 & 0.063 & -2.29 & 0.025 & 2.2 \\
\hline$\Delta$ (Moose hunters) & 0.283 & 0.066 & 4.26 & $<0.001$ & 13.5 \\
\hline County (2 vs 1 ) & 40.60 & 0.066 & 4.27 & 0.001 & \\
\hline County (3 vs 1) & 13.16 & 11.66 & 3.48 & 0.237 & \\
\hline County (4 vs 1 ) & 68.46 & 11.04 & 1.19 & $<0.001$ & \\
\hline County (5 vs 1 ) & 80.48 & 12.22 & 5.60 & $<0.001$ & \\
\hline County (6 vs 1 ) & 56.75 & 12.25 & 6.57 & 0.001 & 35.4 \\
\hline \multicolumn{6}{|l|}{ South Norway } \\
\hline Intercept & 56.18 & 9.587 & 5.86 & $<0.001$ & \\
\hline
\end{tabular}




\begin{tabular}{lrrrrr}
$\Delta$ (Harvest size West)_lag1 & 0.004 & 0.003 & 1.38 & 0.174 & -1.7 \\
$\Delta$ (Harvest size South)_lag1 & 0.264 & 0.081 & 3.26 & 0.002 & 6.0 \\
Year-2010 & -3.156 & 1.065 & -2.96 & 0.005 & 14.9 \\
$($ Year-2010)^2 & -0.939 & 0.270 & -3.47 & 0.001 & 9.7 \\
County (8 vs 7) & 87.20 & 21.42 & 4.07 & $<0.001$ & \\
County (9 vs 7) & 47.53 & 17.48 & 2.72 & 0.009 & \\
County (10 vs 7) & 69.87 & 15.67 & 4.46 & $<0.001$ & 24.0 \\
\hline North Norway & & & & & \\
Intercept & 86.30 & 12.61 & 6.84 & 0.000 & \\
$\Delta$ (Harvest size West)_lag1 & 0.007 & 0.002 & 2.73 & 0.011 & 4.2 \\
$\Delta$ (Harvest size North)_lag1 & -0.075 & 0.092 & -0.82 & 0.421 & -2.3 \\
County (18 vs 17) & -73.20 & 13.08 & -5.60 & $<0.001$ & 15.4 \\
\hline
\end{tabular}


Table 4. Datasets. An overview of the datasets on the movement of hunters at broad scales for all four cervid species in Norway.

\begin{tabular}{|c|c|c|c|c|c|c|c|c|c|}
\hline \multirow[t]{2}{*}{ Species } & \multirow[t]{2}{*}{ Data } & \multirow[t]{2}{*}{$\mathrm{n}$} & \multirow[t]{2}{*}{$\begin{array}{l}\text { Resident } \\
\text { hunters } \\
(\%) \\
\end{array}$} & \multirow[t]{2}{*}{$\begin{array}{l}\text { Mixed } \\
(\%)\end{array}$} & \multirow[t]{2}{*}{$\begin{array}{l}\text { Migratory } \\
\text { hunters (\%) }\end{array}$} & \multicolumn{2}{|c|}{$\begin{array}{l}\text { Euclidean distance } \\
\text { travelled }\end{array}$} & \multicolumn{2}{|c|}{$\begin{array}{l}\text { Google Maps driving } \\
\text { distance }\end{array}$} \\
\hline & & & & & & mean km & median km & mean km & median km \\
\hline \multirow[t]{4}{*}{ Reindeer } & Survey $^{1}$ & 380 & 36.6 & 5.3 & 58.2 & 164.6 & 139.7 & & \\
\hline & $\begin{array}{l}\text { Nordfjella- } \\
\text { communal }\end{array}$ & 216 & 98.6 & & 1.4 & & & & \\
\hline & $\begin{array}{l}\text { Nordfjella- } \\
\text { private }\end{array}$ & 66 & 7.6 & & 92.4 & 143.6 & 149.4 & 216.9 & 221.9 \\
\hline & Knutshø ${ }^{2}$ & 180 & 41.7 & & 58.3 & 142.9 & 139.7 & 209.2 & 206.9 \\
\hline Red deer & Survey & 666 & 51.9 & 12.0 & 36.0 & 133.3 & 77.0 & 204.1 & 122.3 \\
\hline Moose & Survey & 599 & 48.7 & 12.4 & 38.9 & 176.8 & 92.6 & 252.4 & 136.6 \\
\hline \multirow[t]{2}{*}{ Roe deer } & $\begin{array}{l}\text { Statistics } \\
\text { Norway }\end{array}$ & 27675 & 49.8 & & 50.2 & 143.8 & 54.2 & 196.0 & 83.3 \\
\hline & Survey & 480 & 63.8 & 5.6 & 30.6 & 105.5 & 49.0 & 156.3 & 75.0 \\
\hline
\end{tabular}

${ }^{1}$ Measured from the midpoint of the reindeer area (rather than the municipality)

${ }^{2}$ Mixture of private and communal areas 


\section{A}

$\pi$

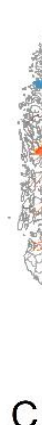

C

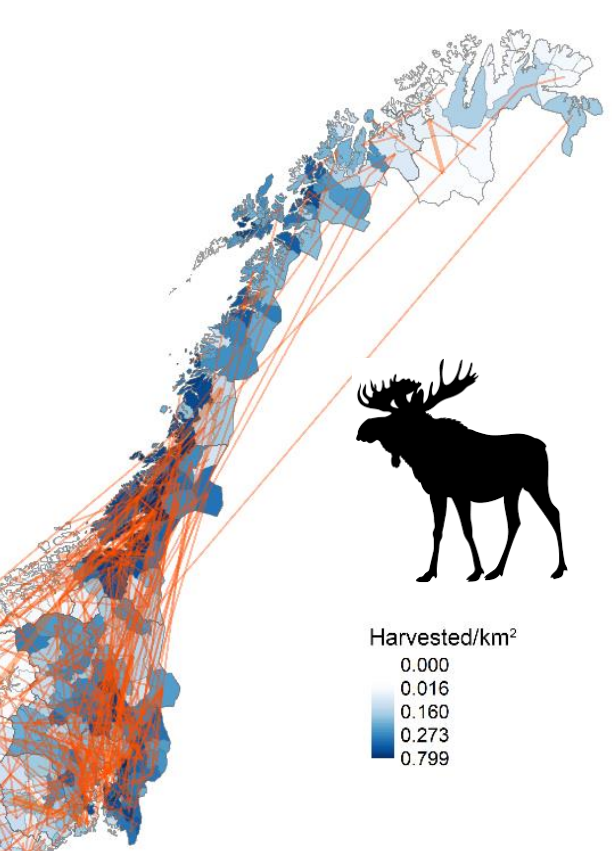

$E$

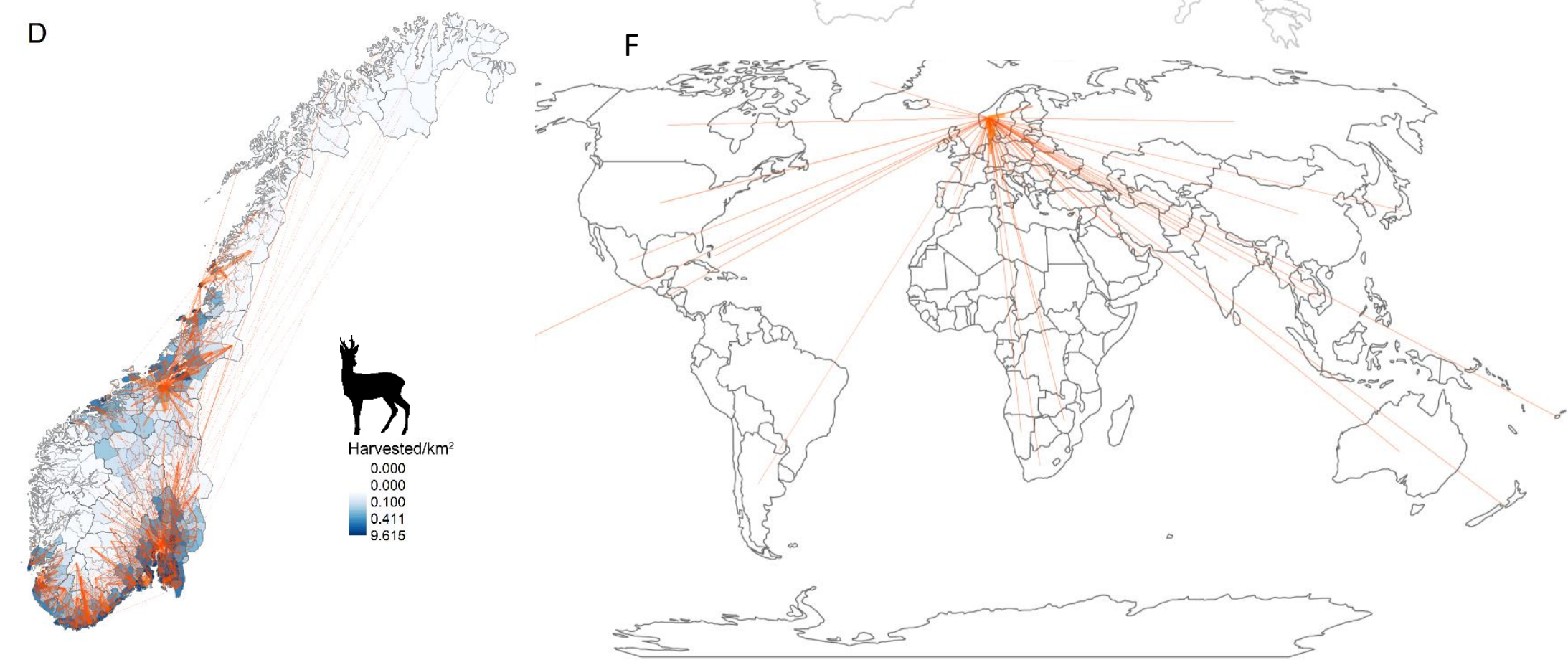

